\title{
CRP and IL-1B Gene Polymorphisms and CRP in Blood in Periodontal Disease
}

\author{
Auerkari $\mathrm{EI}^{1,2, *}$, Suhartono AW ${ }^{1}$, Djamal NZ ${ }^{1}$, Verisqa $\mathrm{F}^{1}$, Suryandari $\mathrm{DA}^{3}$, Kusdhany LS $^{2,4}$, \\ Masulili $\operatorname{SLC}^{5}$ and Talbot $\mathrm{C}^{6}$
}

\author{
${ }^{I}$ Department of Oral Biology, Faculty of Dentistry, University of Indonesia, Jakarta Indonesia \\ ${ }^{2}$ Centre for Ageing Studies, University of Indonesia, Jakarta Indonesia \\ ${ }^{3}$ Department of Medical Biology, Faculty of Medicine, University of Indonesia, Jakarta Indonesia \\ ${ }^{4}$ Department of Prosthodontics, Faculty of Dentistry, University of Indonesia, Jakarta Indonesia \\ ${ }^{5}$ Department of Periodontology, Faculty of Dentistry, Universitas Indonesia, Jakarta, Indonesia \\ ${ }^{6}$ Department of Genetics, University of Leicester, UK
}

\begin{abstract}
Recent studies have suggested an association between periodontal disease (PD) and the systemic polygenic diseases such as cardiovascular disease (CVD). These are thought to be associated because of interrelated environmental, epigenetic, and genetic risk factors. The involved candidate genes include the IL-1B gene, encoding the pro-inflammatory cytokine IL-1 $\beta$, and the CRP gene encoding the C-reactive protein (CRP), also a known marker of inflammation. However, as the details are not well known on the genetic variation influencing the risk factors, this work aimed to evaluate the distribution of selected polymorphisms of IL-1B and CRP genes, and serum CRP level, in comparison with the PD status. For this purpose, periodontal health was assessed, serum CRP levels measured and polymorphism status of IL-1B and CRP genes determined from samples of peripheral blood taken from 101 consenting Indonesian adult males. The results show that severe PD was significantly associated with age and smoking, as expected, but not with the polymorphisms of IL-1B or CRP (1444). However, a significantly lower fraction of subjects with normal periodontal health than subjects with PD showed the heterozygous type polymorphism of CRP (717). There was no significant difference in the fraction of cases with elevated serum CRP level between subjects with normal health and those with PD, and further study with a larger sample is recommended. The observed association between polymorphism of CRP (717) and periodontal health is suggested as a complementary indicator of the risk to PD for the Indonesian male population.
\end{abstract}

Keywords: Periodontal disease, cardiovascular disease, IL-1B, C-reactive protein, polymorphism, serum level.

\section{INTRODUCTION}

Periodontitis is a complex multifactorial disease, usually initiating late and progressing slowly to a chronic phenotype or severe periodontal disease (PD) that is promoted both by environmental factors like smoking, pathogenic bacteria and stress, and by genetic factors [1]. The pathogenesis of PD involves repeated attack of the subgingival bacteria and the host immune defences that result in an inflammatory process contributing to the periodontal tissue destruction. The periodontal structure is a site of unusual opportunity for pathogen attack with the non-shedding tooth surface allowing formation of persistent bacterial biofilms that can maintain proximity to the periodontal tissue $[2,3]$. The initial and reversible gingivitis may develop to periodontitis with the periodontal ligament detaching from cementum to form

*Address correspondence to this author at the Department of Oral Biology, Faculty of Dentistry, University of Indonesia, Jakarta, Indonesia; Tel: +62213910344; Fax: +622131906289;

E-mail: eauerkari@yahoo.com, elza.ibrahim@ui.ac.id periodontal pockets, and the damage extends further to cause alveolar bone resorption, gingival recession, tooth mobility and finally tooth loss. Of the over 300 bacterial species isolated from dental plaque, common Gram-negative species of the periodontal pockets include Aggregatibacter (previously Actinobacillus) actinomycetemcomitans, Porphyromonas gingivalis and Tannerella (previously Bacteroides) forsythus. However, while the bacterial interactions or bacterial plaque are required for the inflammatory condition, they do not explain all cases, for example when periodontitis is observed with little bacterial plaque, or no periodontitis in spite of heavy plaque. The progression and severity of the disease is affected by the strength of the host immune defences and other responses, and the variation in the susceptibility implies an effect of genetic factors [3, 4]. The multifactorial nature of the disease suggests multiple gene associations with a modest or weak individual influence that combined together with other factors have a significant effect on the variation of the manifested outcome [5]. Also other multifactorial diseases like cardiovascular disease (CVD) similarly involve chronic inflammation. CVD is caused by atheroscle- 
rosis (hardening) of blood vessels, the process through which deposit of fatty substances, cholesterol, cellular waste products, calcium and other substances build up in the inner arterial lining. The atherosclerotic plaque will cause symptoms and complications as a result of narrowing of the arterial lumen and narrowing of blood flow to the heart [6]. Epidemiological studies suggest an association between CVD and PD $[2,7,8]$. Suggested mechanisms that can result in such an association include common risk factors including smoking and infections that promote release of proinflammatory cytokines like interleukine-1 or IL-1, and genetic factors related to the regulatory networks of the inflammatory mechanisms [7, 9].

One sensitive marker of inflammation is C-reactive protein (CRP) that is produced particularly in the acute phase of inflammation, infection and trauma in response to proinflammatory cytokines like IL-1 and IL-6 [2]. Single nucleotide polymorphisms (SNP) of IL-1B gene, located on chromosome 2 q13-q21 and which encode the IL-1 $\beta$ cytokine protein, have been reported to be associated with the baseline blood CRP levels of healthy individuals, and it has been suggested that IL-1B regulates the basal CRP levels [3]. Considering the documented evidence on the association between CVD and PD, with expected common genetic risk factors, it is of interest to explore the mechanisms of the association in further detail. The details can be expected to involve the IL-1B gene as one of the primary candidates, and possibly also the CRP gene that is expressed as C-reactive protein in the affected tissue, and in blood. The impact of the genetic variation of particular interest can be assessed by evaluating the polymorphism status in these genes within the population, which in the present case is Indonesian, with respect to the corresponding status of PD. With more detailed information on the mechanisms involved one can hope for improved predictors of risk to CVD, PD, and other systemic chronic disease, and possibly even for routes towards improved therapies.

This work aimed to evaluate the distribution of selected polymorphisms of IL-1B and CRP genes, and serum CRP level with respect to the PD status in a sample from the Indonesian population. Implications were also to be considered on predicting the risk to $\mathrm{PD}$, based on the potential associations between the patterns of polymorphisms, serum CRP level, and the severity of PD.

\section{MATERIALS AND METHODOLOGY}

\section{Subject Recruitment, Classification, and Measurement of CRP Level}

In total, 101 consenting Indonesian male adults were included in this study, with an age range of 25-65 years and median of 39.8 years. The ethical clearance for the work was granted by the Ethical Committee of the Faculty of Dentistry, University of Indonesia and all patients signed written informed consent. Intra oral examination and periodontal health status (plaque index, papillae bleeding index, attachment loss (AL), probing depth) were assessed for all subjects using a standardized procedure at six location on each tooth. For severity of $\mathrm{PD}$, the subjects were divided into three groups: mild / healthy ( $\mathrm{AL} \leq 2 \mathrm{~mm}$ ); moderate ( $\mathrm{AL}>2-4$ $\mathrm{mm}$ ) and severe (AL > $4 \mathrm{~mm}$ ) PD. Examination of clinical attachment loss (CAL) was measured at six tooth surfaces of all teeth. Also, levels of CRP and alkaline phosphatase were measured from peripheral blood samples by using Immunoturbidimetric technique and ALP IFCC Gen2 .

\section{DNA Isolation, PCR Amplification and RFLP Genotyp- ing}

To survey the genotype-phenotype variations related to the gene locus polymorphisms of IL-1B and CRP, the polymorphism status of these genes was determined from samples of peripheral blood.

For isolation of DNA, $3 \mathrm{~mL}$ of peripheral blood was taken from each of the 101 subjects, placed in $15 \mathrm{~mL}$ tubes containing $9 \mathrm{~mL}$ of red blood lysis solution $\left(1.45 \mathrm{M} \mathrm{NH} \mathrm{NH}_{4} \mathrm{Cl}\right.$, $5 \mathrm{mM}$ anhydrous EDTA, and $0.1 \mathrm{M} \mathrm{KHCO}_{3}$ ) and incubated at room temperature for $10 \mathrm{~min}$. The sample was then centrifuged at $1500 \mathrm{rpm}$ for $10 \mathrm{~min}$ at room temperature, and the supernatant was removed to leave a precipitate of mononuclear leukocytes. These steps were repeated to obtain a white pellet and a supernatant containing no red blood cells. To this pellet $2 \mathrm{~mL}$ of cell lysis solution was added and pipetted until homogeneous, and incubated in a water bath at $37^{\circ} \mathrm{C}$ for 30-60 min until completely homogeneous. Then $1.3 \mathrm{~mL}$ of protein precipitation solution (5M ammonium acetate) was added, vortex mixed for 15-20 s and centrifuged at 3000 rpm for $15 \mathrm{~min}$ at $4^{\circ} \mathrm{C}$, producing a light brown precipitate (proteins) and the supernatant containing DNA. The supernatant was poured into a new Falcon tube with $2.3 \mathrm{ml}$ of cold isopropanol. The tube was inverted up to 20-30 times until showing a collection of DNA strands. The supernatant was removed and $1.3 \mathrm{~mL}$ of $70 \%$ ethanol was added for washing, and the DNA solution was centrifuged at $3000 \mathrm{rpm}$ for $5 \mathrm{~min}$ at $4^{\circ} \mathrm{C}$. After discarding supernatant, the DNA was dried in open air by reversing the tube, then DNA was rehydrated with a solution of 200-300 uL TE (Tris-HCl EDTA) and incubated in a water bath at $37^{\circ} \mathrm{C}$ for $2 \mathrm{~h}$. The solution was transferred into $1.5 \mathrm{~mL}$ sterile microcentrifuge tubes and stored at $-20^{\circ} \mathrm{C}$ until further examination.

PCR amplification of DNA fragments was carried out by using Perkin Elmer GeneAmp ® PCR System 9700 with PCR Master Mix, Biomix Red (Bioline). The DNA samples were amplified in 35 cycles of an initial denaturation at $94^{\circ} \mathrm{C}$ for $5 \mathrm{~min}$ and cycles of denaturation, annealing and elongation (primers and PCR optimization are shown in Table 1). The end of the cycle included an extension at $72^{\circ} \mathrm{C}$ for 7 min. After completion the amplicons were stored at $4^{\circ} \mathrm{C}$.

The polymorphisms of IL-1B, CRP717 and CRP1444 were analyzed with PCR-RFLP using the restriction enzymes TaqI, SacII and Bsp, respectively, for cutting at the sites of polymorphisms $[3,5]$. For each amplicon to be cut, the corresponding restriction enzyme was added into $10 \mu \mathrm{L}$ of the amplified DNA fragments, $2 \mu \mathrm{L}$ buffer solution and 18 $\mu \mathrm{L} \mathrm{ddH}_{2} \mathrm{O}$, incubated in water bath at $37^{\circ} \mathrm{C}$ for $3 \mathrm{~h}$ and finally at $65^{\circ} \mathrm{C}$ for $20 \mathrm{~min}$ for enzyme inactivation. For fragment separation, $5 \mu \mathrm{L}$ of the resulting product was mixed with $2 \mu \mathrm{L}$ of tracking dye $(0.25 \%$ bromophenol blue, $0.25 \%$ xylene xyanole, $25 \%$ sucrose) and subjected to electrophoresis on 3\% agarose gel (Promega) containing $1 \mu \mathrm{L}$ ethidium bromide $(0.5 \mathrm{mg} / \mathrm{mL})$ in $1 \mathrm{X}$ TAE buffer solution $(0.04 \mathrm{M}$ 
Table 1. Primers and PCR Cycles for Amplifying the Target Genes

\begin{tabular}{|c|c|c|}
\hline Gene & Primers & PCR cycles \\
\hline \hline \multirow{2}{*}{ IL-1B } & $5^{\prime}$ - CTCAGGTGTCCTCGAAGAAATCAAA-3' & 35 cycles, $94^{\circ} \mathrm{C}\left(30^{\prime \prime}\right), 58^{\circ} \mathrm{C}\left(30^{\prime \prime}\right), 72^{\circ} \mathrm{C}\left(30^{\prime \prime}\right)$ \\
& $5^{\prime}$ - GCTTTTTTGCTGTGAGTCCCG-3' \\
\hline CRP717 & $5^{\prime}$-ACTGGACTTTTACTGTCAGGGC -3' & \\
& $5^{\prime}$-ATCCCATCTATGAGTGAGAACC-3' & 35 cycles, $94^{\circ} \mathrm{C}\left(30^{\prime \prime}\right), 58^{\circ} \mathrm{C}\left(30^{\prime \prime}\right), 72^{\circ} \mathrm{C}\left(30^{\prime \prime}\right)$ \\
\hline CRP1444 & 5'-AGCTCGTTAACTATGCTGGGGCA-3' $^{\prime}$ & 30 cycles $94^{\circ} \mathrm{C}\left(30^{\prime \prime}\right), 62^{\circ} \mathrm{C}\left(30^{\prime \prime}\right), 72^{\circ} \mathrm{C}\left(30^{\prime \prime}\right)$ \\
\hline
\end{tabular}

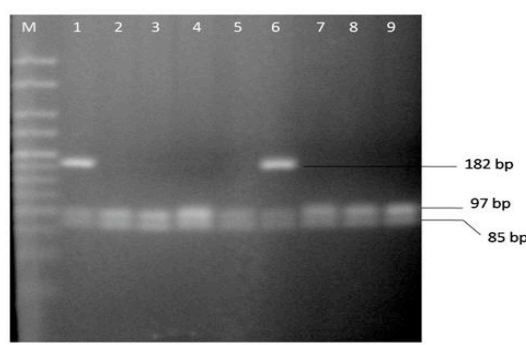

a)

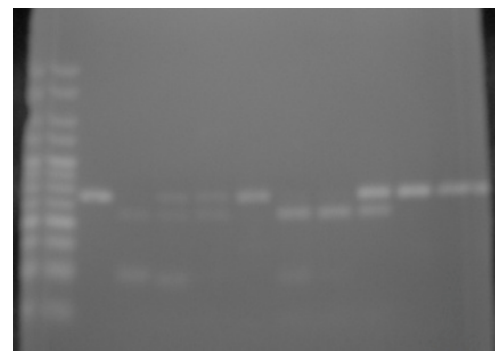

b)

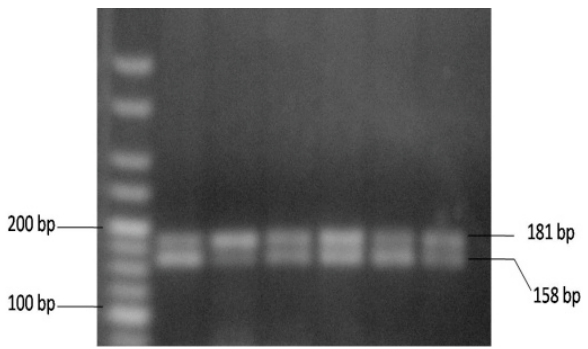

c)

Fig. (1). Fragment separation in electrophoresis to show polymorphisms of a) IL-1B; b) CRP (717) and c) CRP (1444).

Tris-acetate, 0.002 M EDTA $\mathrm{pH} \mathrm{8.0)}$ at $90 \mathrm{~V}$ for $60 \mathrm{~min}$. Using $100 \mathrm{bp}$ DNA ladder markers (Promega), the results were inspected under UV illumination (UV Filter TM Spectroline) and recorded with a digital camera (Fig. 1).

\section{Statistical Analysis}

Chi-square testing with SPSS 18.0 was mainly used in the statistical analysis, both for comparing results in the test groups and for assessing the allele and genotype frequencies with predictions with respect to the Hardy-Weinberg equilibrium. Statistical significance was assumed with $\mathrm{p}<0.05$.

\section{RESULTS}

The results are summarized in Table 2 , where they are divided into groups of normal, moderate and severe periodontal disease. In this classification the normal cases included the lowest number of cases (11). The mean age was highest for the severe PD group, and for all groups SD is similar and also about the same as the difference between the means of the normal and severe PD groups. Of the subjects with severe PD, many fewer were non-smokers $(28.6 \%)$ than smokers (71.4\%). In contrast, $41.7 \%$ of subjects with moderate PD were non-smokers, and only $10.4 \%$ of the subjects in this group (38.1\% in the severe PD group) were heavy smokers with lifetime exposure to at least 100,000 cigarettes. In the normal group, $63.6 \%$ of the subjects were non-smokers and none were heavy smokers. The median and range of lifetime exposure to smoking showed a systematic increase from normal periodontal health to moderate and severe PD groups (Fig. 2). The measured range in the serum levels of C-reactive protein varied between 0.1 and about $20 \mathrm{mg} / \mathrm{L}$.

The most common type of IL-1B polymorphism was the one with common homozygotes (CC), at a frequency of more than $90 \%$ for all groups of PD severity. For the heterozygotes type (CT), three cases $(7.1 \%)$ only appeared in the severe PD group, and for rare homozygotes (TT) only two cases $(4.2 \%)$ in the moderate PD group. For CRP (717) polymorphism, the common homozygotes (SS) occurred at frequencies of $54.2 \% / 59.5 \%$ in the moderate/severe PD groups, but at $90.9 \%$ frequency in the normal group. The heterozygotes (Ss) appeared at frequencies of $37.5 \%$ and $33.3 \%$ in the moderate and severe PD groups, respectively, but not at all in the normal group. The rare homozygotes (ss) were observed at fairly similar though slightly decreasing rates of $9.1 \%, 8.3 \%$, and $7.2 \%$ in the normal, moderate and severe PD groups, respectively. For CRP (1444) polymorphism, the more common homozygotes (BB) appeared only at low and decreasing frequencies of $9.1 \%, 6.25 \%$ and $4.8 \%$ in the same grouping order, while the heterozygotes $(\mathrm{Bb})$ occurred at a frequency of $90 \%$ or higher in all groups, but rare homozygotes (bb) not at all.

\section{DISCUSSION}

In this work the polymorphisms of IL-1B (3954) and CRP $(717,1444)$ genes have been compared to the periodontal health and serum CRP level of 101 Indonesian male subjects. This sample included relatively few normal (healthy) subjects in comparison with the number of those with moderate or severe PD; this largely reflects the unfortunately high prevalence of $\mathrm{PD}$ in the Indonesian population. The results show a clear and expected relationship between PD severity and smoking habit, so that severe PD was significantly associated with higher lifetime smoking exposure, and normal oral condition and moderate PD with non-smokers. Note however that there are clearly other significant contributing factors than smoking (e.g. individual performance levels 
Table 2. Characteristics of the Study Population in Terms of Severity of Periodontal Disease; Age and CRP level as mean \pm SD; LE $=$ Lifetime Exposure as Number of Cigarettes; NS = not Significant

\begin{tabular}{|c|c|c|c|c|}
\hline Variable & Normal & Moderate PD & Severe PD & $\mathbf{P}$ \\
\hline $\mathrm{N}$ & 11 & 48 & 42 & - \\
\hline Age (years) & $35.0 \pm 9.6$ & $37.2 \pm 9.3$ & $44.2 \pm 9.2$ & $0.001^{\text {a) }}$ \\
\hline $\begin{array}{c}\text { Smoking: } \\
\text { Non-smoker } \\
\text { LE }<100000 \\
\text { LE } \geq 100000\end{array}$ & $\begin{array}{c}7(63.6 \%) \\
4(36.4 \%) \\
0(0 \%)\end{array}$ & $\begin{array}{c}20(41.7 \%) \\
23(47.9 \%) \\
5(10.4 \%)\end{array}$ & $\begin{array}{l}12(28.6 \%) \\
14(33.3 \%) \\
16(38.1 \%)\end{array}$ & 0.005 \\
\hline $\begin{array}{c}\mathrm{CRP}(\mathrm{mg} / \mathrm{L}) \\
\mathrm{N} \text { with }>3 \mathrm{mg} / \mathrm{L}\end{array}$ & $\begin{array}{c}2.1 \pm 3.9 \\
1(9.1 \%)\end{array}$ & $\begin{array}{l}2.0 \pm 2.3 \\
8(17.0 \%)\end{array}$ & $\begin{array}{l}2.5 \pm 3.9 \\
8(20.0 \%)\end{array}$ & $\begin{array}{l}0.743 \mathrm{NS}^{\mathrm{a})} \\
0.491 \mathrm{NS}\end{array}$ \\
\hline $\begin{array}{c}\text { IL-1B (3954): } \\
\text { CC } \\
\text { CT } \\
\text { TT }\end{array}$ & $\begin{array}{c}11(100 \%) \\
0(0 \%) \\
0(0 \%)\end{array}$ & $\begin{array}{c}46(95.8 \%) \\
0(0 \%) \\
2(4.2 \%)\end{array}$ & $\begin{array}{c}39(92.9 \%) \\
3(7.1 \%) \\
0(0 \%)\end{array}$ & $0.587 \mathrm{NS}$ \\
\hline $\begin{array}{c}\text { CRP (717): } \\
\text { SS } \\
\text { Ss } \\
\text { ss }\end{array}$ & $\begin{array}{c}10(90.9 \%) \\
0(0 \%) \\
1(9.1 \%)\end{array}$ & $\begin{array}{c}26(54.2 \%) \\
18(37.5 \%) \\
4(8.3 \%)\end{array}$ & $\begin{array}{c}25(59.5 \%) \\
14(33.3 \%) \\
3(7.2 \%)\end{array}$ & 0.047 \\
\hline $\begin{array}{c}\text { CRP (1444): } \\
\begin{array}{c}\mathrm{BB} \\
\mathrm{Bb} \\
\mathrm{bb}\end{array}\end{array}$ & $\begin{array}{c}1(9.1 \%) \\
10(90.9 \%) \\
0(0 \%)\end{array}$ & $\begin{array}{c}3(6.25 \%) \\
45(93.75 \%) \\
0(0 \%)\end{array}$ & $\begin{array}{c}2(4.8 \%) \\
40(95.2 \%) \\
0(0 \%)\end{array}$ & $0.857 \mathrm{NS}$ \\
\hline
\end{tabular}

a) Kruskal-Wallis test

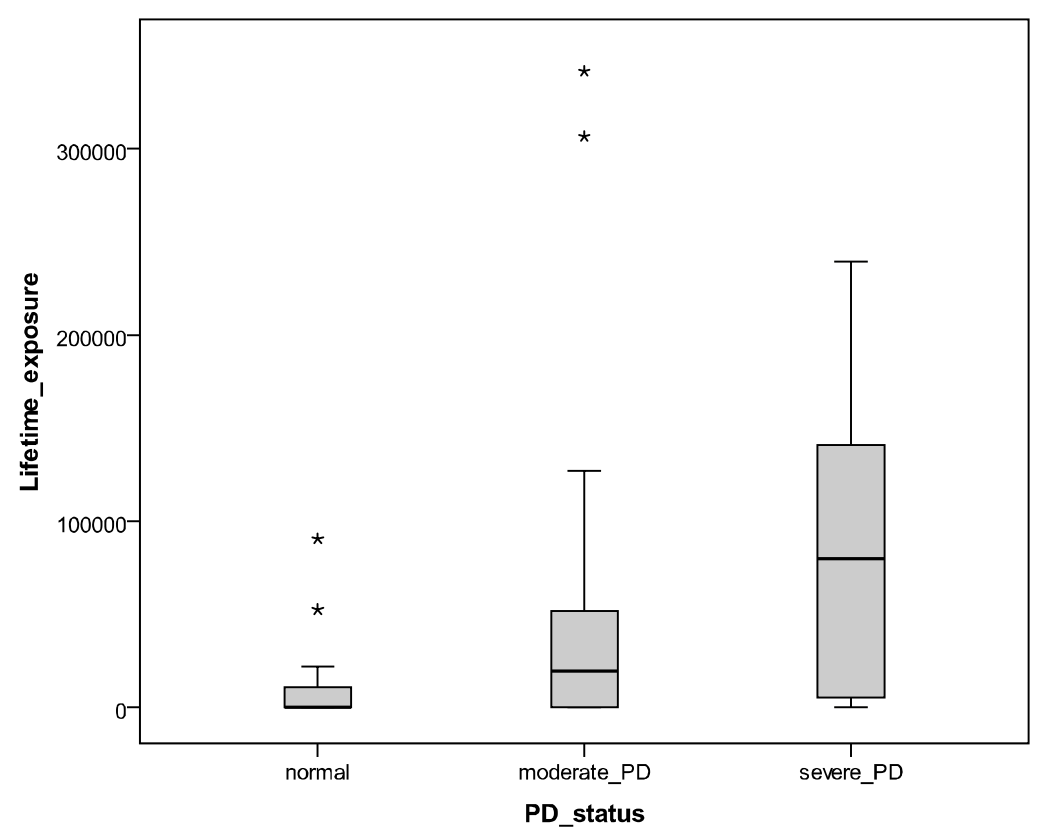

Fig. (2). Impact of the estimated number of smoked cigarettes during lifetime for subject groups of normal periodontal health, moderate PD and severe PD (asterisks refer to outlier cases).

of oral hygiene and immune response), as is seen from the increasing scatter in the lifetime exposure with the severity of PD in Fig. (2). Also an expected association with age was seen, so that the mean age of the subjects with severe PD was higher than for those with normal oral health and moderate PD. However, the grouping of normal condition, moderate PD and severe PD was not significantly associated with the polymorphisms of IL-1B or CRP (1444) in the sample 
population. The only exception was CRP (717) where the heterogeneous type in normal subjects occurred at a significantly lower fraction of cases than in subjects with PD; even here, no significant difference was seen between subjects with moderate and severe PD. The levels of serum CRP were varying strongly in all groups of PD severity, but the fraction of subjects with serum CRP level above $3 \mathrm{mg} / \mathrm{L}$ was lower for cases of normal periodontal health than for cases of moderate or severe PD. A large scatter is not unexpected since inflammation other than that related to PD can have much influence on the serum CRP levels.

The pro-inflammatory IL-1B can be blocked with the IL1 receptor antagonist IL-1Ra (anakinra) that has been approved for treatment of some chronic autoinflammatory diseases like rheumatoid arthritis [8]. Until recently the IL-1 family only consisted of two main members (IL-1A and IL1B) but has considerably expanded to include at least 11 members of which some like IL-18, IL-36A, IL-36B, and IL$36 \mathrm{G}$ are also pro-inflammatory factors, and some others appear antagonist or anti-inflammatory (IL-1Ra, IL-36Ra, IL37) or with unknown function (IL-38). With only partially known receptors and coreceptors, their overall roles remain to be described in detail but are likely to be fairly complex judging from the known signalling networks related of IL-1B [9]. The observed frequencies of IL-1B (3954) genotype CC (Table 2) were clearly higher (more than 90\%) in this work for Indonesian male adults than what has been reported previously for European subjects [15].

Chronic periodontitis typically involves a persistent infection of the periodontal pocket by Gram-negative bacteria like A. actinomycetemcomitans. This micro-organism produces a leucotoxin that induces degranulation and lysis in human neutrophils, caspase-1 activation, and abundant secretion of IL-1 $\beta$ from human macrophages, promoting tissue destruction including loss of alveolar bone $[9,10]$. Therefore the periodontal induction of IL-1B activity by the bacterial leucotoxin largely explains tooth loss in advanced PD. With local periodontal inflammation mediated by IL- $1 \beta$ that also enters circulation, the observed association is perhaps to be expected with CVD, another chronic systemic disease promoted by pro-inflammatory cytokines $[2,9,11,14]$. Nevertheless, the reported association between PD and CVD, and associations with them and individual polymorphisms of IL1 and CRP genes, can be diluted by the complex polygenic nature of the overall regulatory networks with a relatively small contribution by any single gene. If the associations between individual genes and their polymorphisms are relatively weak, this also means that the individual polymorphisms alone are not particularly powerful risk indicators to such disease. While the conventional indicators may remain more useful, like the directly measured extent of pocket depth and alveolar bone loss for PD, and high blood pressure, smoking, obesity, and CRP level for CVD, successful treatment of PD can reduce inflammation and circulating IL1 and CRP levels, with potentially reduced risk to CVD $[12,13,16,17]$. Also, potential additional indicators like CRP (717) polymorphism status may serve as a complementary factor to the current array of standard indicators, at least if it can be in future more conveniently tested.

\section{CONCLUSION}

A significantly lower fraction of subjects with normal periodontal health than those with PD showed the heterogeneous type polymorphism of CRP (717) that hence may provide a complementary indicator of the risk to PD. In contrast, no significant association was found between periodontal health and the polymorphisms of IL-1B or CRP (1444) in the Indonesian male sample population. However, considering the currently available evidence [16-18], the association between PD and CVD appears to remain sufficient to justify informing patients with severe PD that they may have an increased risk of CVD.

As the number of the subjects with a normal periodontal health in this work was relatively small, confirmation with further study of a larger sample population is necessary.

\section{CONFLICT OF INTEREST}

The authors confirm that this article content has no conflicts of interest.

\section{ACKNOWLEDGEMENTS}

The authors wish to gratefully acknowledge the financial support from the University of Indonesia (DRPM-UI 2010) and the Ministry of Education and Culture of the Republic of Indonesia.

\section{REFERENCES}

[1] Laine ML, Loos BG, Crielaard W. Gene polymorphisms in chronic periodontitis. Int J Dent 2010; 324719.

[2] Pizzo G, Guiglia R, Russo LL, Campisi G. Dentistry and internal medicine: from the focal infection theory to the periodontal medicine concept. Eur J Intern Med 2010; 21: 496-502.

[3] Eklund C, Jahan F, Pessi T, Lehtimäki T, Hurme M. Interleukin 1B gene polymorphism is associated with baseline $\mathrm{C}$-reactive protein levels in healthy individuals. Eur Cytokine Netw 2003; 14: 168-71.

[4] Li X, Tse HF, Jin LJ. Novel endothelial biomarkers: implications for periodontal disease and CVD. J Dental Res 2011; 90(9): $1062-$ 9.

[5] Takashiba S, Naruishi K. Gene polymorphisms in periodontal health and disease. Periodontol 2000 2006; 40: 94-106.

[6] Weissberg PL. Atherogenesis: current understanding of the causes of the atheroma. Heart 2000; 83: 247-52.

[7] Libby P, Crea F. Clinical implications of inflammation for cardiovascular primary prevention. Eur Heart J 2010; 31: 777-83.

[8] Karnoutsos K, Papastergiou P, Stefanidis S, Vakaloudi A. Periodontitis as a risk factor for cardiovascular disease: the role of antiphosphorylcholine and anti-cardiolipin antibodies. Hippokratia 2008; 12: 144-9.

[9] Dinarello CA. Interleukin-1 in the pathogenesis and treatment of inflammatory diseases. Blood 2011; 117: 3720-32.

[10] Kelk P, Claesson R, Chen C, Sjostedt A, Johansson A. IL-1beta secretion induced by Aggregatibacter (Actinobacillus) actinomycetemcomitans is mainly caused by leucotoxin. Int J Med Microbiol 2008; 298: 529-41.

[11] Geismar K, Enevold C, Korsbaek, et al. Involvement of interleukin-1 genotypes in the association of coronary heart disease with periodontitis. J Periodontol 2008; 79: 2322-30.

[12] Bis JC, Heckbert SR, Smith NL, et al. Variation in inflammationrelated genes and risk of incident nonfatal myocardial infarction or ischemic stroke. Atherosclerosis 2008; 198: 166-73.

[13] Kumar DS. Evaluation of serum C-reactive protein in patients with chronic periodontitis before and after periodontal therapy. Master Thesis. Bangalore, India: Rajiv Gandhi University of Health Sciences, 2006; p. $120+$ annex.

[14] Mucci LA, Hsieh C-C, Williams P, et al. Do genetic factors explain the association between poor oral health and cardiovascular dis- 
ease? a prospective study among Swedish twins. Am J Epidemiol 2009; 170: 615-21.

[15] Ricci M, Garoia F, Tabarroni C, et al. Association between genetic risk score and periodontitis onset and progression: a pilot study. Arch Oral Biol 2011; 56 (12): 1499-505

[16] Bahekar AA, Singh S, Saha S, Molnar J, Arora R. The prevalence and incidence of coronary heart disease is significantly increased in periodontitis: a meta-analysis. Am Heart J 2007; 154: 830-7.
[17]

Kuo L-C, Polson AM, Kang T. Associations between periodontal diseases and systemic diseases: a review of the inter-relationships and interactions with diabetes, respiratory diseases, cardiovascular diseases and osteoporosis. Public Health 2008; 122: 417-33.

[18] Friedewald VE, Kornman KS, Beck JD, et al. Editors' Consensus: Periodontitis and atherosclerotic cardiovascular disease. Am J Cardiol 2009; 104: 59-68.

Received: March 20,2013

Revised: March 27, 2013

Accepted: March 27, 2013

(C) Auerkari et al.; Licensee Bentham Open.

This is an open access article licensed under the terms of the Creative Commons Attribution Non-Commercial License (http://creativecommons.org/licenses/by-nc/3.0/) which permits unrestricted, non-commercial use, distribution and reproduction in any medium, provided the work is properly cited. 